\title{
Pu multi-recycling scenarios towards a PWR fleet for a stabilization of spent fuel inventories in France
}

\author{
Fanny Courtin ${ }^{1,}$, Camille Laguerre ${ }^{1}$, Philippe Miranda ${ }^{1}$, Christine Chabert $^{2}$, and Guillaume Martin ${ }^{1}$ \\ ${ }^{1}$ DES/IRESNE/DER/SPRC/LE2C, CEA Cadarache, 13115 Saint Paul-lez-Durance, France \\ 2 DES/IRESNE/DER, CEA Cadarache, 13115 Saint Paul-lez-Durance, France
}

Received: 16 July 2021 / Received in final form: 22 October 2021 / Accepted: 8 November 2021

\begin{abstract}
Nuclear scenario studies are performed to explore the impact of possible evolutions of nuclear fleets. The nuclear fuel cycle simulation tool COSI, developed by CEA, is used to model these dynamic scenarios and to evaluate them with respect to uranium and plutonium management, fuel reprocessing and waste production. In recent years, scenarios have focused on transitions from the current nuclear French fleet to a deployment of SFR. However, the French Multi-annual Energy Planning has recently postponed the deployment of this technology to the second half of the 21st century. Alternative solutions of plutonium management in PWR are investigated to stabilize total inventories of spent nuclear fuels. The MIX concept is based on homogeneous fuel assemblies where fuel rods are composed of plutonium blended with enriched uranium. In this study, a transition from the current French fleet to an EPR ${ }^{\mathrm{TM}}$ fleet is simulated. Two power capacities of the future $\mathrm{EPR}^{\mathrm{TM}}$ fleet are considered. A progressive deployment of fuel multi-recycling in the $\mathrm{EPR}^{\mathrm{TM}}$ fleet is implemented to enable stabilization of all spent fuels and plutonium inventories. Natural uranium consumption is also minimized thanks to ERU fuel batches in $\mathrm{EPR}^{\mathrm{TM}}$. Results are compared with plutonium and uranium mono-recycling in a PWR fleet.
\end{abstract}

\section{Introduction}

Nuclear scenario studies aim to explore possible prospective developments of nuclear fleets. Within this framework, scenarios are designed, in France, within the limits of conservative criteria defined and validated with the French industry: EDF, ORANO and FRAMATOME. These criteria ensure the scenario realism as regards our current knowledge of safety, regulation, technology and costs. The COSI6 software developed by CEA [1], which relies on the CESAR5.3 [2] irradiation and evolution simulation code, is used to simulate these scenarios and to evaluate them with respect to uranium $(\mathrm{U})$ and plutonium $(\mathrm{Pu})$ management, spent fuel (SF) reprocessing and wastes production.

Nuclear scenarios in France have focused these recent years on the development of Sodium Fast Reactor (SFR) technology [3]. A progressive deployment of SFR in the French nuclear fleet has been studied to recycle $\mathrm{Pu}$ from spent PWR MOX fuels. Indeed, in the current French fleet, $\mathrm{Pu}$ in UOX spent fuels is currently recycled into MOX fuel assemblies. $\mathrm{Pu}$ in MOX spent fuels is characterized by a fissile grade lower than $\mathrm{Pu}$ in UOX fuel limiting its recycling into fresh MOX fuels. At each recycling, the fissile content in the $\mathrm{Pu}$ vector is degraded

\footnotetext{
* e-mail: fanny.courtin@cea
}

(increase of Pu240 and Pu242 contents and decrease of Pu239 and $\mathrm{Pu} 241$ contents in the $\mathrm{Pu}$ vector). This leads to a necessary increase of $\mathrm{Pu}$ content in fresh fuel at each recycling to reach the targeted burn-up. However, $\mathrm{Pu}$ content in fresh PWR MOX fuels is limited for safety reasons [4]. Thus, SFR technology deployment is considered to recycle spent MOX fuels, stabilize $\mathrm{Pu}$ total inventory, and ultimately close the fuel cycle. However, the French Multi-annual Energy Planning (PPE) [5] has recently postponed the deployment of this technology to the second half of the 21st century. Alternative solutions of Pu management in $\mathrm{PWR}$ are therefore investigated to recycle $\mathrm{Pu}$ from MOX spent fuels [6,7]. To allow for $\mathrm{Pu}$ multi-recycling in PWR, fuel assemblies using enriched uranium along with recycled $\mathrm{Pu}$ have been designed. PWR MIX assembly is considered in this study. MIX refers to an assembly where fuel rods are composed of $\mathrm{Pu}$ oxide mixed with enriched uranium oxide [8].

This study aims to explore trajectories involving the deployment of $\mathrm{Pu}$ multi-recycling in PWR - and are therefore useful from a research and development perspective - but do not constitute the reference evolution for the French fleet to this date. Hypotheses used for those simulations are continuously upgraded in collaboration with industrial partners, as research on cycle plants and reactor designs advances. 
Table 1. EPR characteristics (EPR / EPR2) for various fuel batches.

\begin{tabular}{lllll}
\hline Reactor & Fuel & EFPD & Discharge burnup (MWd/t) & Nominal power (MWe) \\
\hline EPR FLA3 & UOX & 517 & 50000 & 1492 \\
& UOX & 437 & 50000 & \\
\multirow{2}{*}{ EPR2 } & ERU & 437 & 50000 & 1670 \\
& $30 \%$ MOX & 405 & UOX: 49000 & \\
& MIX $8 \%$ & 437 & MOX: 47000 & 50000 \\
\hline
\end{tabular}

Table 2. Inventories of nuclear matters and spent fuels from the last HCTISN report [10] compared with their simulated equivalents.

\begin{tabular}{lll}
\hline Inventories at the end of 2016 & HCTISN report [10] & COSI6 simulation \\
\hline Depleted U from nat. U enrichment & $293 \mathrm{kt}_{\mathrm{HM}}$ & $293,1 \mathrm{kt}_{\mathrm{HM}}$ \\
Reprocessed uranium & $26,93 \mathrm{kt}_{\mathrm{HM}}$ & $26,86 \mathrm{kt}_{\mathrm{HM}}$ \\
Separated Pu (outside fabrication plants) & $43,8 \mathrm{t}_{\mathrm{HM}}$ & $43,8 \mathrm{t}_{\mathrm{HM}}$ \\
UOX spent fuels & $11360 \mathrm{t}_{\mathrm{HM}}$ & $11367 \mathrm{t}_{\mathrm{HM}}$ \\
ERU spent fuels & $578 \mathrm{t}_{\mathrm{HM}}$ & $580 \mathrm{t}_{\mathrm{HM}}$ \\
MOX spent fuels & $1830 \mathrm{t}_{\mathrm{HM}}$ & $1832 \mathrm{t}_{\mathrm{HM}}$ \\
\hline
\end{tabular}

\section{Scenario assumptions}

\subsection{COSI6 simulation}

These studies have been carried out using the scenario code COSI6 [1]. This code, developed by CEA, is based on discrete events simulation. COSI6 can simulate the dynamic evolution of a nuclear fleet with its associated cycle plants and repositories. Equivalence models [9], based on neural networks or regression, are used to estimate the composition of fresh fuels: here U235 enrichment in MIX and ERU (enriched reprocessed uranium) and Pu content in MOX. COSI6 is coupled with the evolution code CESAR [2] to calculate the composition of fuels in reactor cores or in storage conditions: this is currently the reference evolution code for the La Hague reprocessing plant. It solves the Bateman equation for 109 heavy nuclides and over 200 fission products using the nuclear database JEFF3.1.1, and 1-group cross-section libraries for reactor modelling.

\subsection{EPR of the future fleet}

The future fleet is composed entirely of European Pressurized Reactors (EPR) in their second version (EPR2), except for the EPR of Flamanville (FLA3), which is currently under construction. The lifespan of all the EPR is 60 years, and their load factor $83 \%$. Table 1 gathers the characteristics of EPR fuel batches simulated here.

MIX assemblies are here composed of $100 \%$ of mixed $(\mathrm{U}, \mathrm{Pu})$ fuel rods with enriched uranium. $\mathrm{Pu}$ content of fresh rods is fixed, here to $8 \%$ mass, therefore, the U235 enrichment of their uranium support is adjusted to compensate for the decrease of their $\mathrm{Pu}$ fissile grade under multi-recycling conditions.

\subsection{From the current PWR fleet to the next EPR fleet}

A detailed simulation of the current French fleet from its beginnings is performed with COSI6 and adjusted in order to fit with the inventories of spent fuels and nuclear matters reported in the last report of the French Committee for Transparency and Information on Nuclear Safety (HCTISN) [10]. Table 2 shows a good correspondence between the simulation and the data at the end of the year 2016.

The decrease of nuclear share to $50 \%$ of the French electricity mix is currently planned by 2035 [5]. However, the electrification of industry and transport are a way to decarbonize the economy. It supposes a large increase in electricity production that, if it were sufficient, would allow the nuclear contribution to reach $50 \%$ of total French electricity production without significant drop in capacity. Two trajectories are therefore studied here:

- $\mathrm{T}_{\text {constant }}$ : with an almost constant capacity - 32 EPR2 deployed, for a total reference power of $53 \mathrm{GWe}$;

- $\mathrm{T}_{\text {decrease: }}$ with a significant drop in the installed power 18 EPR2 deployed for a total reference power of $30 \mathrm{GWe}$.

\subsection{Fuel cycle}

In the two scenarios, fuel fabrication plants adapt their capacity to the needs of the reactors, with an anticipation of exactly 2 years that corresponds to the time considered for their fabrication. The other stages of the cycle are assumed instantaneous. Material losses at the fuel frontend are neglected, except for $0.5 \%$ mass losses at the conversion plant until 2050. 


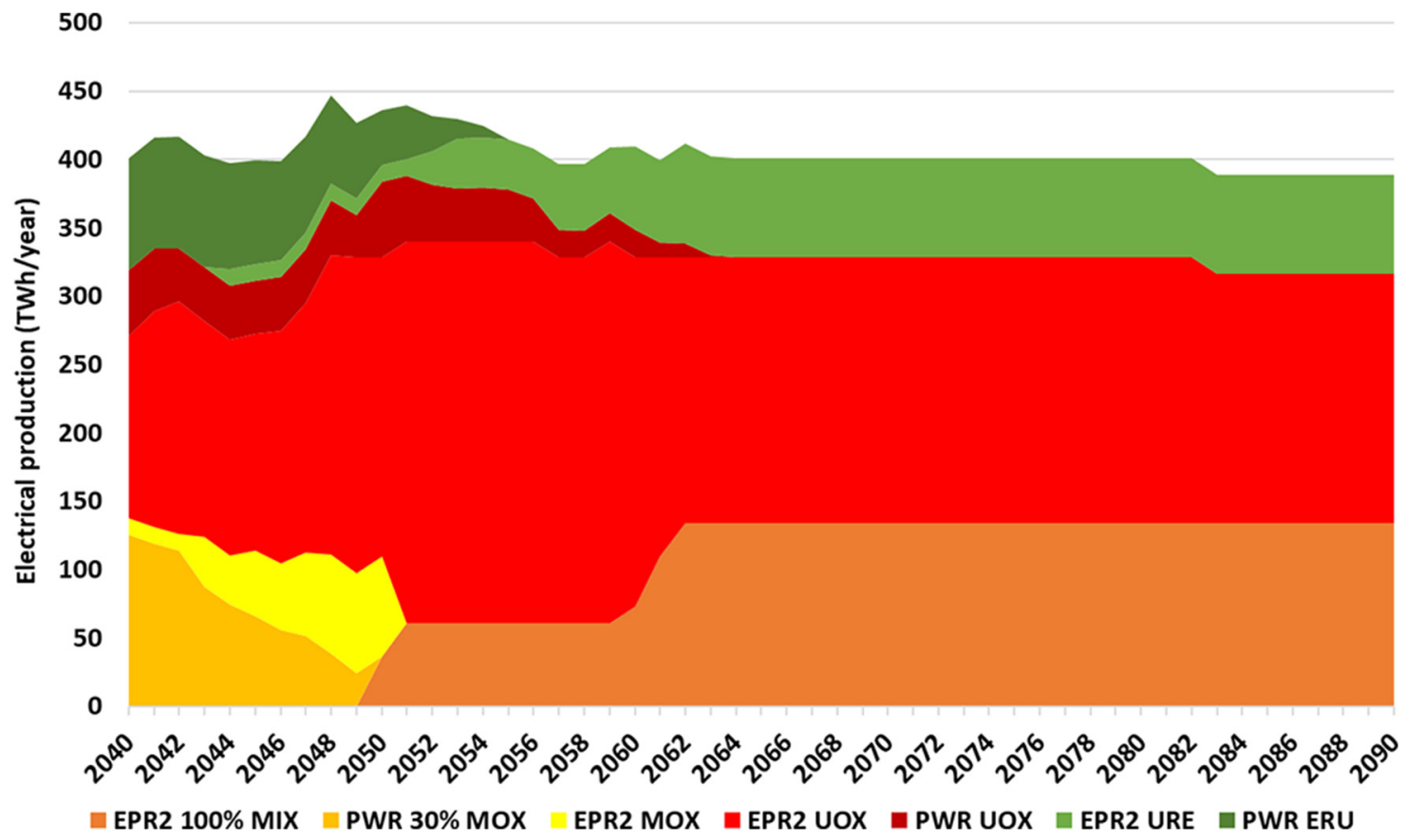

Fig. 1. Planning of reactors and cycle during the $T_{\text {constant }}$ scenario.

Industrial realism limits impose that only one type of $\mathrm{Pu}$-based fuel is fabricated in the fabrication plant. When the new $\mathrm{Pu}$-based fuel fabrication plant produces MIX fuel, standard MOX fabrication stops. All types of spent fuel must have cooled at least 5 years before reprocessing [3]. The reprocessing capacity of La Hague plant is simulated until 2016 from the data reported in the last HCTISN report [10]. In addition, the replacement of the current La Hague (SF reprocessing) and Mélox (MOX fabrication) plants occurs in 2048 in this study. Hence, MIX fuel made from $\mathrm{Pu}$ ex-MOX could be loaded in EPR as soon as 2050. $0.3 \%$ of the reprocessed $\mathrm{Pu}$ is lost in glass packages, and $0.16 \%$ in the shells, for a total loss of Pu of $0.46 \%$ by mass at reprocessing.

\subsection{Scenario objectives}

The objectives of the scenarios were set in workgroup meetings involving EDF, ORANO, FRAMATOME and CEA, and are reported below in order of priority:

- the total $\mathrm{Pu}$ inventory must be stabilized as soon as possible, and before the end of the century. This includes in particular the stabilization of all spent fuel inventories, as required by the government issued PPE of 2019 [5].

- the reprocessing of ERU spent fuels is carried out in the new reprocessing plant as soon as it starts, in 2048. Enough ERU batches are introduced in the fleet to induce a slow reduction of the reprocessed uranium inventory.

- the reprocessing capacity of MOX spent fuels should has as little variations as possible in the future plant, with a complete recovery of all these SF by the end of the century and as soon as possible. In practice, the fabrication of MOX batches stops when MIX batches are deployed. MOX spent fuels should not be reprocessed at a higher capacity than MIX spent fuel reprocessing capacity at fleet steady-state. The fast reprocessing of all the residual MOX fuels is a way to move towards multirecycling in just-in-time flow of all the spent fuels produced by the EPR2 fleet: UOX, ERU and MIX exclusively. However, this raises the question of the rate of MOX SF reprocessing. In a previous work [6], a capacity of more than $400 \mathrm{t}_{\mathrm{HM}} / \mathrm{yr}$ was ultimately considered excessive. For this reason, in these scenarios, reprocessing of MOX spent fuels is limited to $200 \mathrm{t}_{\mathrm{HM}} / \mathrm{yr}$. - in the future fleet, the production of minor actinides is minimized by reprocessing in priority the MIX spent fuels that have just been unloaded (LIFO withdrawal). However, the fraction of fuels withdrawn in LIFO mode must remain limited, so that the maximal cooling period of SF never exceeds 100 years, to be consistent with French nuclear safety authority (ASN) decision [11]. Under these assumptions, it is possible to estimate the maximum fraction of SF withdrawn in LIFO mode $(90 \%$ for MIX). For the remaining part, older spent fuels are reprocessed first.

\section{Scenario results}

\subsection{Planning and electrical production}

Three periods can be identified in both scenarios. During the first period, the current fleet is replaced by a future fleet of EPR2, deployed from the early 2030's. The second period consists in the introduction of MOX fuels in several EPR2s in the decade 2040, in order to maintain the fabrication rate of MOX fuels in the current plant by the middle of the century. The third part is the deployment of the multi- 


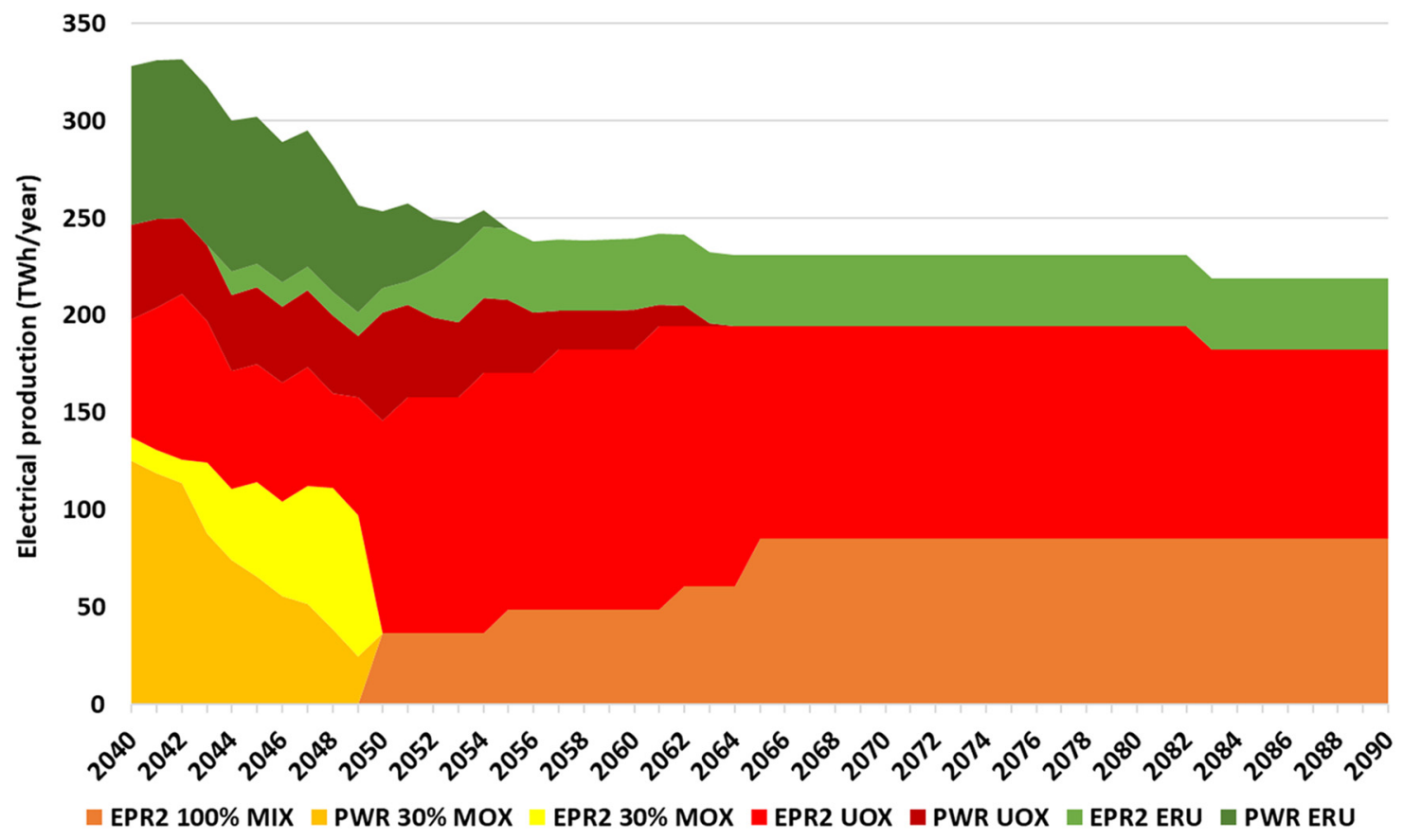

Fig. 2. Planning of reactors and cycle during the $T_{\text {decrease }}$ scenario.

recycling fleet, with the first MIX batches introduced in EPR2 from 2050. This last phase relies on two new plants: the reprocessing and fabrication plants which are deployed in 2048, in anticipation of 2 years of the first MIX batches. Figures 1 and 2 show the evolution of the French fleet from the current situation to the deployment of the new multirecycling fleets, in $\mathrm{T}_{\text {constant }}$ and $\mathrm{T}_{\text {decrease }}$ scenarios.

In $T_{\text {constant }}$ scenario, the electrical production remains almost stable during this century, for a reference power of the EPR2 fleet that eventually reaches 53 GWe. In $T_{\text {decrease }}$ scenario, the electrical production decreases until a power capacity of $30 \mathrm{GWe}$ is reached. In both cases, fleet compositions, especially MIX fraction in the fleet, are adjusted to stabilize the $\mathrm{Pu}$ and spent fuels inventories. In these fleets, the MIX fraction allowing balancing $\mathrm{Pu}$ and spent fuels inventories is around 38\%. Furthermore, several EPR2 supplied with ERU fuels are deployed to induce a slow decrease of the reprocessing uranium inventory.

\subsection{Fuel cycle front-end}

\subsubsection{Natural uranium consumption}

Natural uranium has different uses: it supplies the fabrication of standard enriched UOX fuel during the entirety of the scenario, and MIX fuel batches fabrication starting in 2048. Indeed, MIX assemblies are 100\% composed of rods based on $\mathrm{Pu}$ and enriched uranium to compensate for the decrease of the $\mathrm{Pu}$ fissile grade.

Figure 3 shows both the cumulated and the annual natural uranium consumption during the scenarios. The difference between the cumulated consumptions for both trajectories is consistent with the size of both fleets. A high increase in annual natural uranium consumption occurs during the $T_{\text {constant }}$ scenario between 2045 and 2055: this is

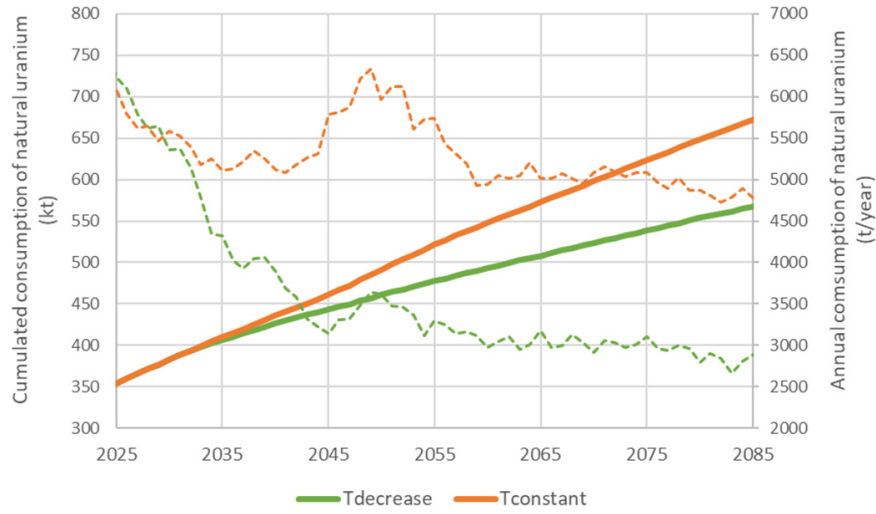

Fig. 3. Natural uranium consumptions - cumulated and annual.

explained, on the first order, by the loading of a significant amount of entire new UOX cores during the transition. Such an increase does not appear in the case of $T_{\text {decrease }}$, since there are less entire cores to fabricate, and their fabrication also happens at a time of decrease of the total amount of reactors, and therefore of natural uranium consumption.

In both cases, the annual uranium consumption dedicated to MIX increases over time. This is inherent to multi recycling of $\mathrm{Pu}$ using the MIX design. Indeed, in MIX, as the fissile grade of the $\mathrm{Pu}$ falls, the enrichment of the uranium support increases, hence a higher consumption of natural resources: it is therefore relatively low at their introduction in 2050, and grows thereafter. This enrichment remains lower than in UOX fuel however (see Sect. 3.2.3), hence an overall decrease in the annual natural uranium consumption appears. 


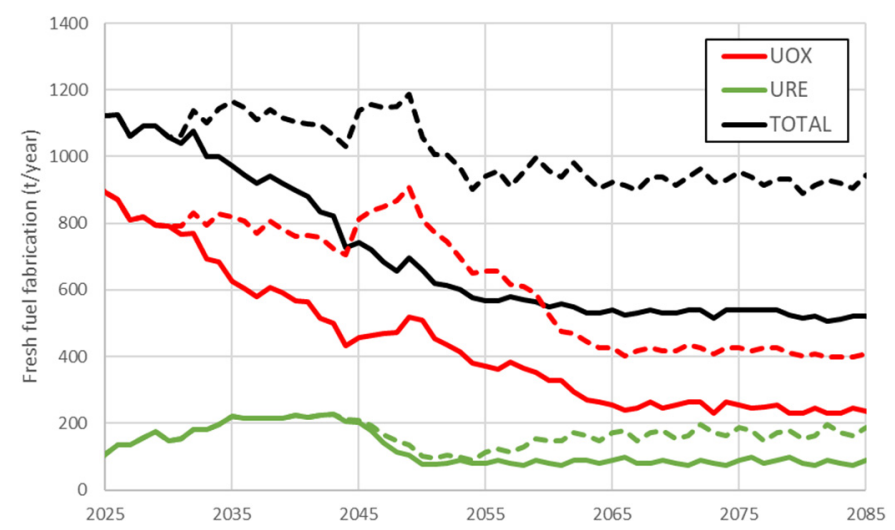

Fig. 4. Fabrication of UOX and ERU fuels (averaged over 5 years).

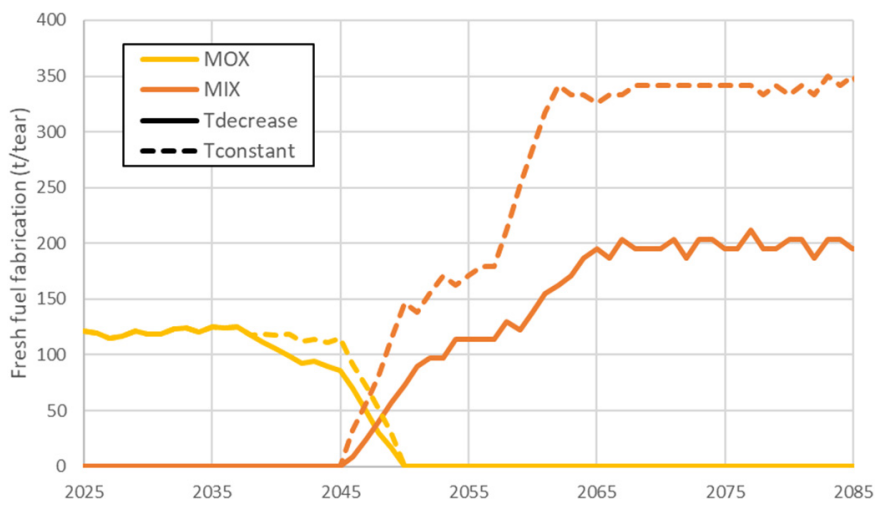

Fig. 5. Fabrication of MOX and MIX fuels (averaged over 5 years).

\subsubsection{Fuel fabrication}

Figure 4 shows the differences in the total, as well as UOX and ERU fuels assembly fabrication capacities for both trajectories. For the figure to be more readable, fabrication capacities are averaged over 5 years. The differences between both cases is once again consistent with the respective sizes of the fleets. As discussed in previous section, an increase in UOX fuel fabrication occurs during the $T_{\text {constant }}$ scenario between 2045 and 2055. Figure 5 gathers the fabrication of $\mathrm{Pu}$-based fuels. In both cases, the deployment rate of MIX EPR2 and the closure rate of MOX fuels are balanced in order to maintain a constant fabrication capacity in the current Mélox plant, until it stops in 2048.

The fabrication rate of $\mathrm{Pu}$-based fuels in the new plant increases gradually towards the capacity of the EPR2 fleet at equilibrium - determined by the number of reactors supplied with MIX - by the end of the century, reaching 200 or 340t/yr depending on the trajectory, which remains significantly higher than the current one at Mélox facility $(120 \mathrm{t} / \mathrm{yr})$.

\subsubsection{Composition of fresh MIX fuels}

U235 enrichment and $\mathrm{Pu}$ isotopic compositions in MIX fresh fuels are presented in Figures 6-8 for scenarios $T_{\text {decrease }}$ and $T_{\text {constant }}$. By finely adjusting the mixture of

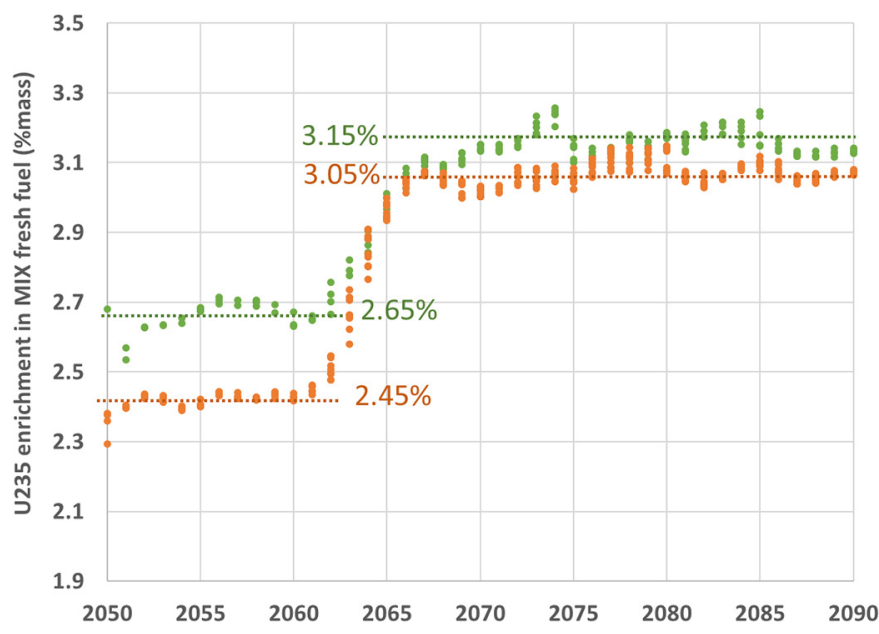

Fig. 6. Steps of U235 enrichment of U in MIX rods.

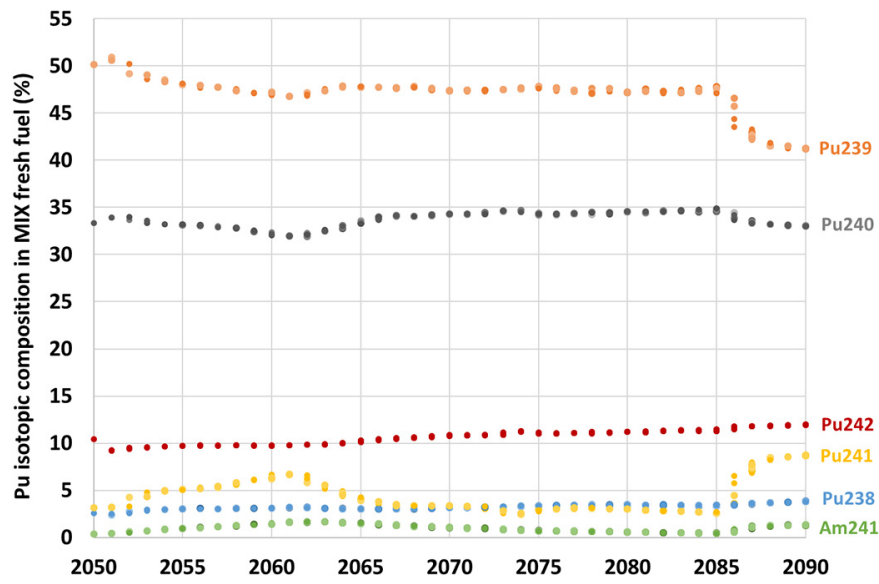

Fig. 7. $\mathrm{Pu}$ isotopy in MIX fresh fuels in scenarios $T_{\text {decrease }}$.

spent fuels at reprocessing (see Sect. 3.3.1), U235 enrichment in fresh MIX fuels was maintained within $0.1 \%$ around two steps. In both scenario, three distinct periods can be identified with regard to the isotopic evolution of the $\mathrm{Pu}$ of fresh MIX fuels, in particular with respect to their Pu241 content:

- during this first period - that corresponds to the first enrichment content step, MOX spent fuels are the only $\mathrm{Pu}$-based fuels that are withdrawn. Hot MOX spent fuels unloaded from EPR2 and in a lesser extent from the last PWRs, are still available. They are relatively rich in Pu241. A relatively low level of U235 enrichment is obtained, higher in $T_{\text {decrease }}$ compared to $T_{\text {constant }}$. Indeed, to ensure spent MOX fuels reprocessing before 2090, $170 \mathrm{tHM} / \mathrm{yr}$ of these spent fuels are reprocessed in $T_{\text {decrease }}$ option. This leads to a rate of $30 \%$ of MOX in the spent fuel mixture, whereas it is $20 \%$ in $T_{\text {constant }}$ option (see Sect. 3.3.1).

- hot MOX spent fuels have been entirely reprocessed. Only MOX spent fuels from the current French fleet are available for reprocessing. $\mathrm{Pu}$ in these spent fuels 


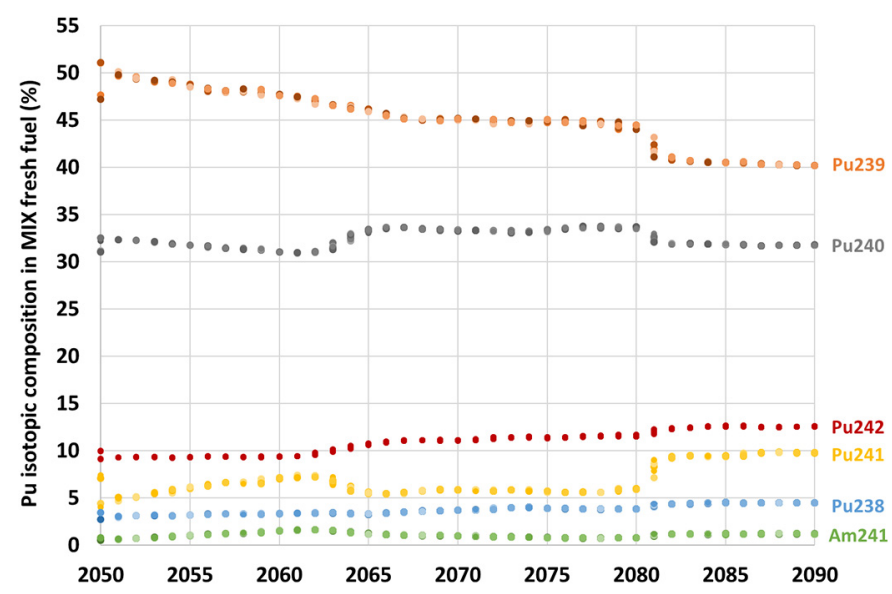

Fig. 8. Pu isotopy in MIX fresh fuels in scenarios $T_{\text {constant }}$.

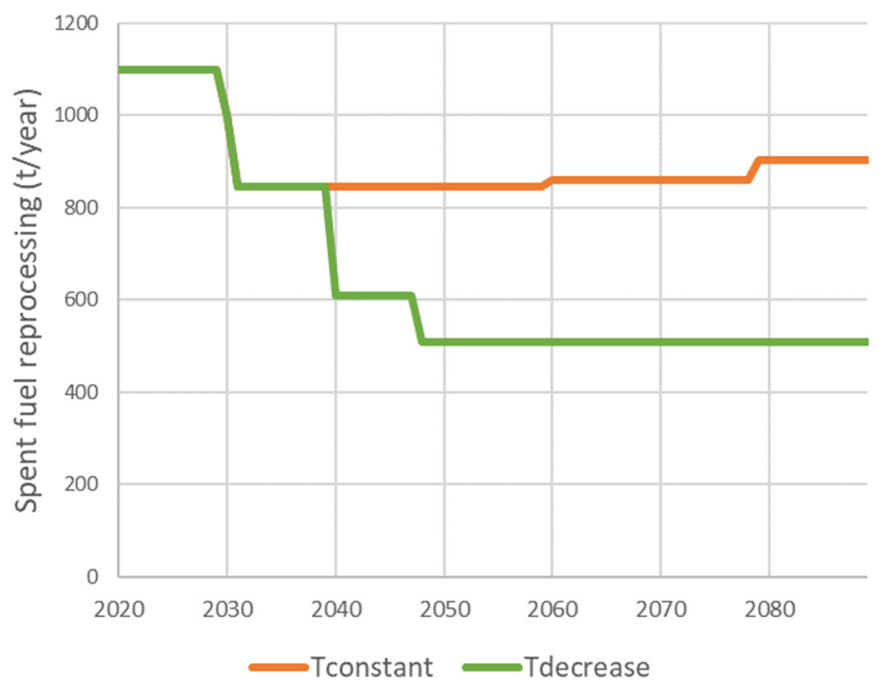

Fig. 9. Total reprocessing capacity of all spent fuels.

contains almost no Pu241, its fissile quality is relatively low, and the enrichment content in multi-recycling fuels increases in compensation. The second step of U235 enrichment starts. In $T_{\text {constant }}$, first MIX spent fuels are reprocessed in addition to MOX spent fuels to provide $\mathrm{Pu}$ needed for the deployment of the EPR2 multi-recycling fleet, whereas MOX reprocessing remains limited to 200 tHM/yr by assumption (see Sect. 2.5).

- in the last period all MOX spent fuels have been reprocessed, and the just in time reprocessing of MIX fuels can proceed for a stabilization of both the $\mathrm{Pu}$ total inventory and spent fuels quantities. The hottest MIX spent fuels are reprocessed first as much as possible (see Sect. 2.5). Thus, Pu241 content increases in new fuels and U235 enrichment is kept constant at the second level.

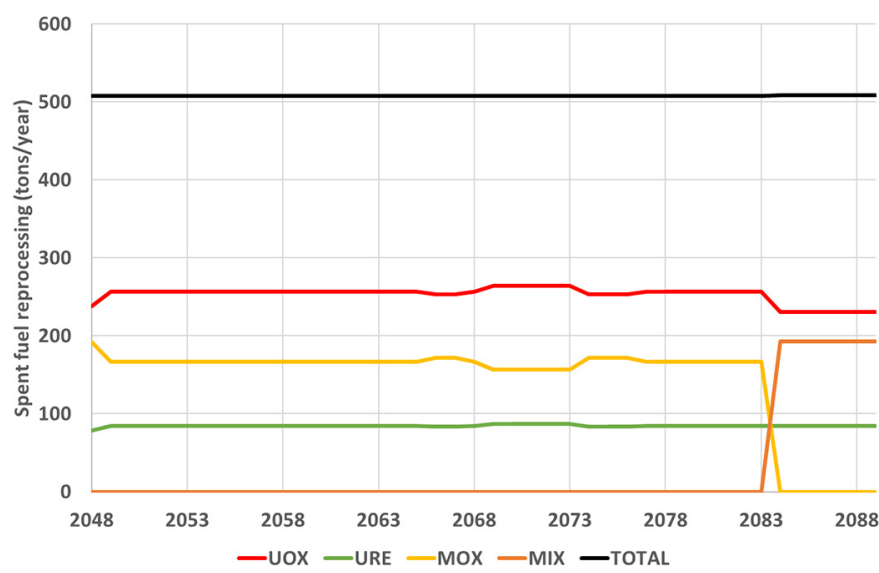

Fig. 10. Reprocessing of spent fuels during scenarios $T_{\text {decrease }}$

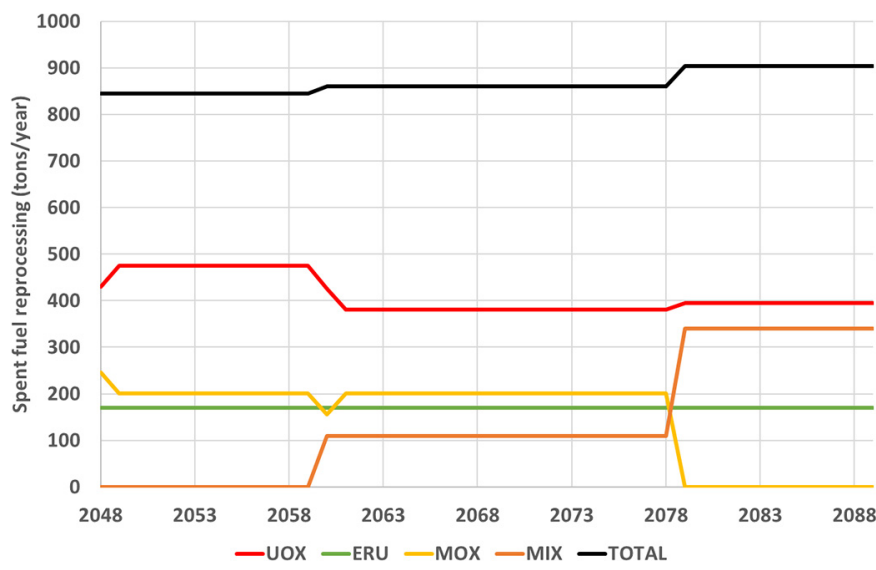

Fig. 11. Reprocessing of spent fuels during scenarios $T_{\text {constant }}$.

\subsection{Fuel cycle back-end}

\subsubsection{Spent fuels reprocessing}

The reprocessing capacity of all the spent fuels during multi-recycling scenarios is presented in Figure 9. Until 2040, the total capacity is fixed by assumption (see Sect. 2.4), after which it follows several steps to progressively converge towards the capacity that eventually reprocesses all the spent fuels produced by the multirecycling EPR2 fleets. Thus in the first order, the total reprocessing capacity depends on the fleet power.

Reprocessing of each type of spent fuels in the new plant is detailed in Figures 10 and 11 for the two scenarios. In $T_{\text {decrease }}$, reprocessing capacities are relatively smooth over two successive periods: reprocessing of all MOX SF followed by just in time reprocessing of MIX SF. In $T_{\text {constant }}$, three periods occur: reprocessing of MOX SF, joint reprocessing of MOX and MIX SF and just in time reprocessing of MIX SF. In both cases, some small 


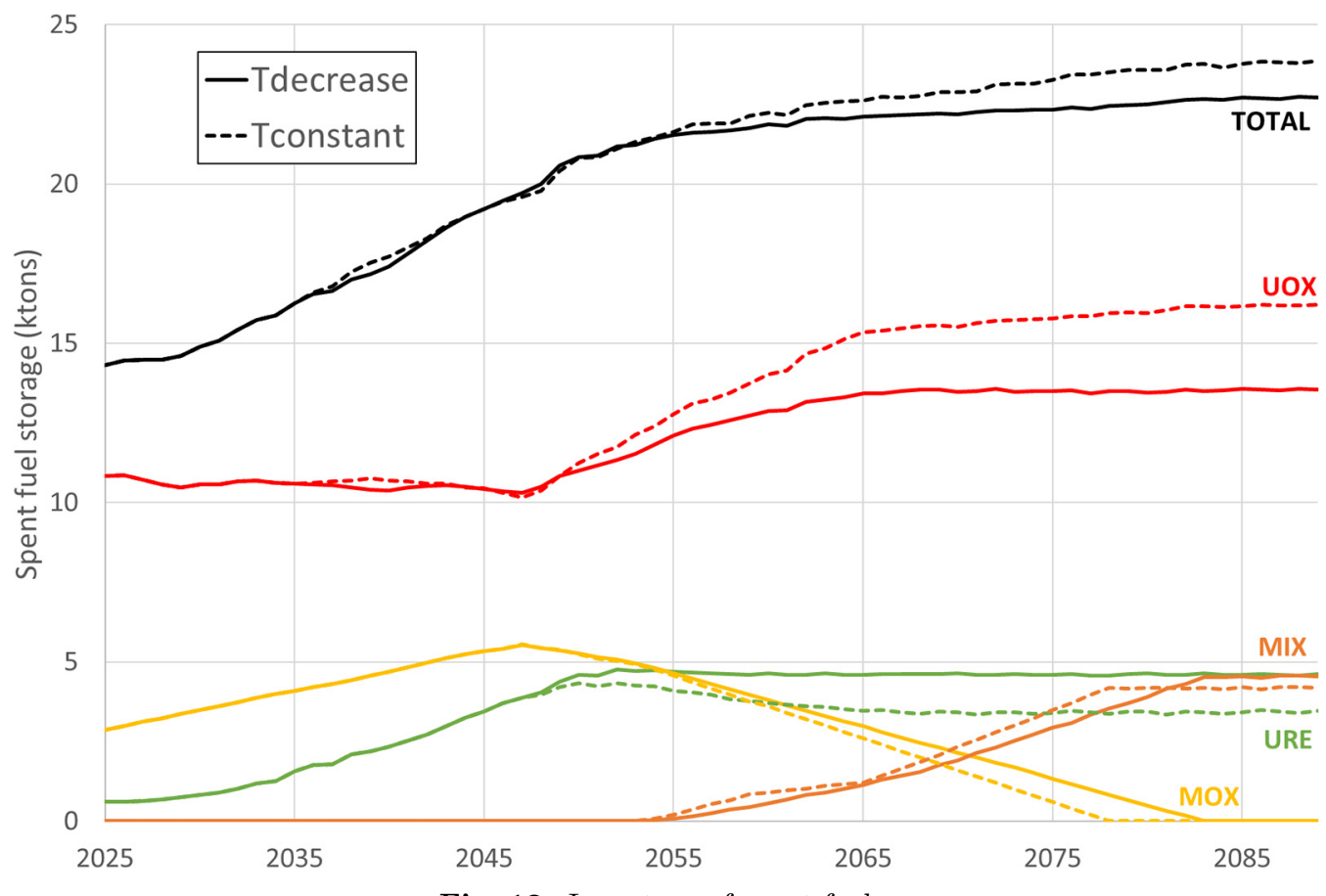

Fig. 12. Inventory of spent fuels.

variations of reprocessing capacities are introduced to smooth the U235 enrichment of fresh MIX fuels (see Sect. 3.2.3).

\subsubsection{Spent fuel inventory}

Figure 12 groups together the evolution of the quantity of spent fuels: total, MOX, MIX, UOX and ERU. Both scenarios come to stabilize the spent fuels inventories by the end of the century in accordance with the objectives of the current French PPE [5].

Recycling the $\mathrm{Pu}$-based fuels that are discharged from the fleet motivated in some extent these multi-recycling studies in PWR without SFR. The different scenarios reveal the capacity of the various multi-recycling fuel batches to take back all the MOX spent fuels before the end of the century. MOX spent fuels are completely recycled in 2078 in the case of $T_{\text {constant }}$, thanks to the associated higher reprocessing capacity. This goal might even be reached sooner if the pace at which MOX recycling occurs is allowed to exceed $200 \mathrm{tHM} /$ year (see Sect. 2.5). In $T_{\text {decrease, }}$ due to a lower reprocessing capacity, MOX spent fuels are completely recycled in 2083.

\subsection{3 $\mathrm{Pu}$ and MA total inventories}

The inventories of total $\mathrm{Pu}$ and minor actinides (here: Am, $\mathrm{Np}$ and $\mathrm{Cm}$ ) in both scenarios are presented in Figure 13 and Figure 14 and compared to a mono-recycling option applied to trajectories $T_{\text {decrease }}$ and $T_{\text {constant }}$. In the mono-recycling strategy, $\mathrm{Pu}$ and $\mathrm{U}$ extracted from reprocessed UOX spent fuels are recycled in MOX and ERU batches in EPR. Spent MOX and ERU fuels are not reprocessed. Total $\mathrm{Pu}$ inventories stabilize by the end of the century, which satisfies the second objective of the French PPE [5]. What primarily determines the quantity of $\mathrm{Pu}$ and minor actinides quantities produced by a fleet is its size. Secondarily, multi-recycling in PWR produces more minor actinides than once-through cycle and mono-recycling current French fleet $[6,8]$.

\section{Conclusion}

Recent French PPE [5] has postponed the deployment of SFR technology to the second half of the 21st century. In the meantime, alternative solutions of $\mathrm{Pu}$ management in PWR are investigated. PWR MIX assembly has been considered in this study. MIX refers to an assembly where fuel rods are composed of $\mathrm{Pu}$ oxide mixed with enriched uranium oxide [8].

In this study, transitions from the current French fleet to EPR fleets are simulated with the scenario code COSI6, within the limits of conservative criteria defined and validated with the French industry: EDF, ORANO and FRAMATOME.

Two installed power trajectories were considered. $T_{\text {constant }}$ is characterized by an almost constant capacity (32 EPR2 deployed, for a total reference power of $53 \mathrm{GWe}$ ). $T_{\text {decrease }}$ is characterized by a significant drop in the 


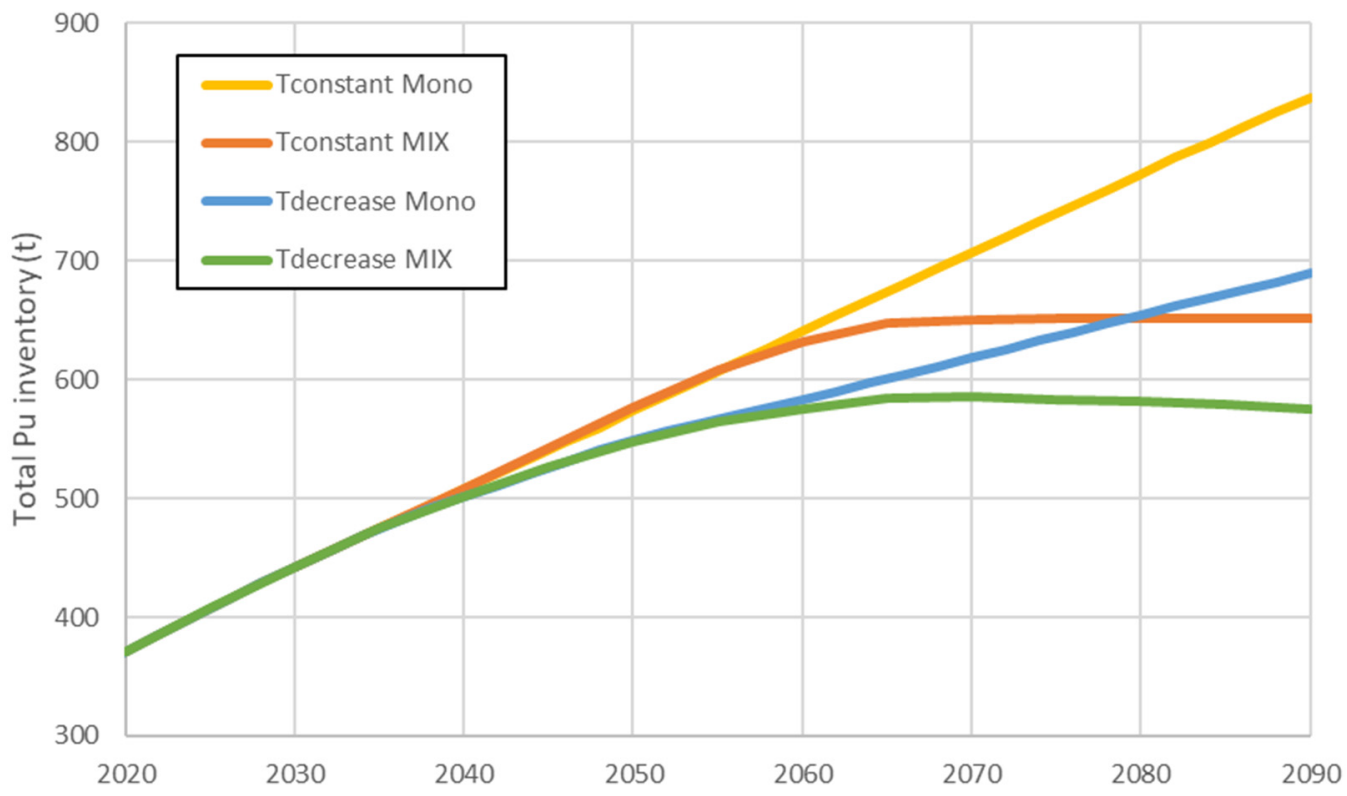

Fig. 13. Total $\mathrm{Pu}$ inventory.

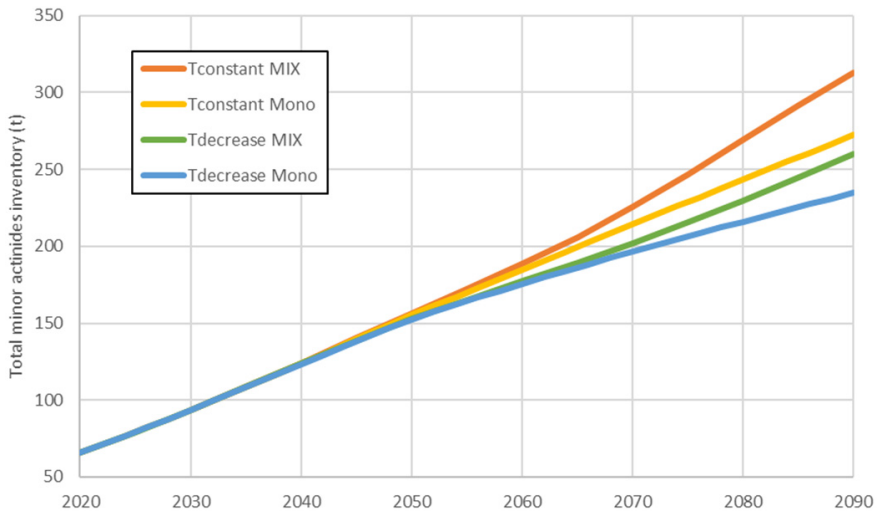

Fig. 14. Total minor actinides inventory.

installed power (18 EPR2 deployed for a total reference power of $30 \mathrm{GWe}$ ). In these scenarios, four objectives were selected: stabilization of $\mathrm{Pu}$ inventory and all spent fuel inventories, deployment of ERU batches to induce a slow reduction of the reprocessed uranium inventory, spent MOX fuels reprocessing as soon as possible (within the limit of MIX spent fuels reprocessing at fleet steady-state) and minimization of minor actinides production. Table 3 gathers the performance indicators that characterize the multi-recycling fleet and their equivalent in monorecycling strategy in 2090. In mono-recycling strategies, $\mathrm{Pu}$ and reprocessed uranium extracted from UOX SF reprocessing are used to fabricate MOX and ERU batches. MOX and ERU fractions in the fleets are adjusted to stabilize UOX SF inventory. MOX and ERU SF are not reprocessed.
The MIX fraction in these fleets is around 38\%. This fraction has been set to this value in order to stabilize $\mathrm{Pu}$ inventory in the fleet, to meet the first objective.

Natural uranium consumption is slightly lower in multi-recycling options compared to mono-recycling options. However, mono-recycling strategy in $T_{\text {constant }}$ contains only 5 EPR ERU compared to 6 in the case of MIX option. With regard to spent fuel inventories, both multi-recycling scenarios reprocess all the MOX spent fuels before the end of the century. Due to its higher reprocessing capacity at steady-state, MIX fleet in $T_{\text {constant }}$ scenario is able to reprocessed all MOX spent fuels 5 years sooner than the fleet associated to $T_{\text {decrease }}$ scenario. Both MIX fleets operate a just-in-time reprocessing of spent fuels inventories when there is no more MOX spent fuels to recycle: spent fuel inventories are then stabilized. Total $\mathrm{Pu}$ inventory is also stabilized in both cases. The levels at which the $\mathrm{Pu}$ inventory stabilizes depends primarily on the power trajectory followed. In multi-recycling fleets, minor actinides production is $30 \%$ to $50 \%$ higher than in mono-recycling fleets. Forthcoming work could be to study the transition from these fleets to a SFR deployment during the next century.

The presented trajectories have been designed in order to explore the deployment of $\mathrm{Pu}$ multi-recycling in PWR and do not constitute the reference evolution for the French fleet to this date. Hypotheses used for those simulations are continuously upgraded in collaboration with industrial partners, as research on cycle plants and reactor designs advances.

This work was supported by EDF, ORANO and FRAMATOME. 
Table 3. Performances of multi-recycling fleets compared with mono-recycling strategy.

\begin{tabular}{|c|c|c|c|c|}
\hline \multirow{2}{*}{ Results in 2090} & \multicolumn{2}{|c|}{$T_{\text {constant }}$} & \multicolumn{2}{|c|}{$T_{\text {decrease }}$} \\
\hline & Mono-recycling & MIX $8 \%$ & Mono-recycling & MIX $8 \%$ \\
\hline \multirow{3}{*}{ Fleet composition } & 18 EPR UOX & 14 EPR UOX & 10 EPR UOX & 8 EPR UOX \\
\hline & 5 EPR ERU & 6 EPR ERU & 3 EPR ERU & 3 EPR ERU \\
\hline & $9 \mathrm{EPR} 30 \% \mathrm{MOX}$ & 12 EPR MIX & $5 \mathrm{EPR} 30 \% \mathrm{MOX}$ & 7 EPR MIX \\
\hline Natural U consomption & $700 \mathrm{kt}+5.2 \mathrm{kt} / \mathrm{y}$ & $691 \mathrm{kt}+4.7 \mathrm{kt} / \mathrm{y}$ & $580 \mathrm{kt}+2.9 \mathrm{kt} / \mathrm{y}$ & $578 \mathrm{kt}+2.7 \mathrm{kt} / \mathrm{y}$ \\
\hline Annual reprocessing & $720 \mathrm{tHM} / \mathrm{y}$ & $903 \mathrm{tHM} / \mathrm{y}$ & $420 \mathrm{tHM} / \mathrm{y}$ & $508 \mathrm{tHM} / \mathrm{y}$ \\
\hline \multirow[t]{5}{*}{ Spent Fuel (tHM) } & Total: $27200+215 \mathrm{t} / \mathrm{y}$ & Total: 23860 & Total: $24300+125 \mathrm{t} / \mathrm{y}$ & Total: 22710 \\
\hline & UOX: 8000 & UOX: 16210 & UOX: 8200 & UOX: 13550 \\
\hline & ERU: $9700+135 t / y$ & ERU: 3460 & ERU: $8400+80 \mathrm{t} / \mathrm{y}$ & ERU: 4620 \\
\hline & MOX: $9500+80 \mathrm{t} / \mathrm{y}$ & MIX: 4190 & MOX: $7700+45 \mathrm{t} / \mathrm{y}$ & MIX: 4540 \\
\hline & & MOX: 0 in 2079 & & MOX: 0 in 2084 \\
\hline $\mathbf{P u}$ & $840 \mathrm{t}+6.5 \mathrm{t} / \mathrm{y}$ & $650 \mathrm{t}$ & $690 \mathrm{t}+3.5 \mathrm{t} / \mathrm{y}$ & $575 \mathrm{t}$ \\
\hline Minor Actinides & $272 \mathrm{t}+2.9 \mathrm{t} / \mathrm{y}$ & $310 \mathrm{t}+4.3 \mathrm{t} / \mathrm{y}$ & $235 \mathrm{t}+1.9 \mathrm{t} / \mathrm{y}$ & $255 \mathrm{t}+2.9 \mathrm{t} / \mathrm{y}$ \\
\hline
\end{tabular}

\section{Author contribution statement}

The work presented in this paper is produced in the framework of the CEA CYN/STECY project managed by Christine Chabert. All authors have contributed to the design of the scenarios and the analysis of the results. Fanny Courtin, Philippe Miranda and Guillaume Martin have run the calculations. Fanny Courtin, Guillaume Martin and Camille Laguerre have written this paper.

\section{References}

1. C. Coquelet-Pascal, M. Tiphine, G. Krivtchik et al., COSI6: a tool for nuclear transition scenario studies and application to SFR deployment scenarios with minor actinide transmutation, Nucl. Technol. 192, 91-110 (2015)

2. J.-M. Vidal, R. Eschbach, A. Launay et al., CESAR5. 3: an industrial tool for nuclear fuel and waste characterization with associated qualification - 12067, in WM2012 Conference, 2012

3. G. Martin, Study of a mixed fleet of breeder sfr and epr supplied with leu and mox fuels to balance the plutonium inventory, in ICAPP, 2018
4. S. Aniel, J. Bergeron, A. Puill, Evaluation of the maximum content of a MOX-fueled pressurized water reactor versus isotopic composition with respect to the void coefficient, IAEA-TECDOC (1997) vol. 941

5. Ministère de la transition écologique, Stratégie française pour l'énergie et le climat, Programmation pluriannuelle de l'énergie 2019-2023, 2024-2028, (2019) https://www.ecologie.gouv.fr/

6. G. Martin, M. Guyot, F. Laugier et al., French scenarios toward fast plutonium multi-recycling in PWR, in ICAPP (2018)

7. F. Courtin, N. Thiollière, X. Doligez et al., Assessment of plutonium inventory management in the french nuclear fleet with the fuel cycle simulator CLASS, Nucl. Eng. Des. 377 (2021)

8. G. Youniou, A. Vasile, Plutonium multirecycling in standard PWRs loaded with evolutionary fuels, Nucl. Sci. Eng. 151, 25-45 (2005)

9. G. Krivtchik, P. Blaise, C. Coquelet-Pascal, Artificial neural network surrogate development of equivalence models for nuclear data uncertainty propagation in scenario studies, EPJ Nucl. Sci. Technol. 3, 22 (2017)

10. Haut Comité pour la Transparence et l'Information sur la Sécurité Nucléaire, Présentation du Cycle du combustible, français en 2018, Rapport du 27 juillet 2018

11. Autorité de sûreté nucléaire, Avis no 2020-AV-0363, 8 octobre 2020

Cite this article as: Fanny Courtin, Camille Laguerre, Philippe Miranda, Christine Chabert, Guillaume Martin, Pu multirecycling scenarios towards a PWR fleet for a stabilization of spent fuel inventories in France, EPJ Nuclear Sci. Technol. 7, 23 $(2021)$ 